\title{
Association of the malnutrition-inflammation score with anthropometry and body composition measurements in patients with chronic kidney disease
}

\author{
Wen-Ling Wang ${ }^{1,2}$, Shuang Liang ${ }^{1}$, Fang-Lei Zhu ${ }^{1}$, Jie-Qiong Liu ${ }^{1}$, Xiang-Mei Chen ${ }^{1}$, Guang-Yan Cai ${ }^{1}$ \\ ${ }^{1}$ Department of Nephrology, Chinese PLA General Hospital, Chinese PLA Institute of Nephrology, State Key Laboratory of Kidney Diseases, \\ National Clinical Research Center for Kidney Diseases, Beijing Key Laboratory of Kidney Disease, Beijing 100853, China; ${ }^{2}$ General Internal \\ Medicine Department, the Fifth Medical Center of Chinese PLA General Hospital, Beijing 100039, China \\ Contributions: (I) Conception and design: GY Cai, WL Wang; (II) Administrative support: GY Cai, XM Chen; (III) Provision of study materials or \\ patients: GY Cai, XM Chen; (IV) Collection and assembly of data: WL Wang, FL Zhu, JQ Liu; (V) Data analysis and interpretation: WL Wang, S \\ Liang; (VI) Manuscript writing: All authors; (VII) Final approval of manuscript: All authors. \\ Correspondence to: Guang-Yan Cai. Department of Nephrology, Chinese PLA General Hospital, Chinese PLA Institute of Nephrology, State Key \\ Laboratory of Kidney Diseases, National Clinical Research Center for Kidney Diseases, Beijing Key Laboratory of Kidney Disease, 28 Fuxing Road, \\ Beijing 100853, China. Email: caiguangyan@sina.com.
}

Background: The malnutrition-inflammation score (MIS) is a nutritional scoring system that has been validated in chronic kidney disease (CKD) stages III-V, especially in dialysis patients. We aimed to test whether the MIS changed in the early stages of CKD and whether it was associated with anthropometry and body composition measurements (BCMs) in patients with CKD.

Methods: This was a cross-sectional study conducted in the Nephrology Department. A total of 144 patients with CKD were included in the study between May 2017 and December 2017. The MIS was calculated without computing the dialysis vintage in the scoring. Body composition was measured using a portable whole-body bioimpedance spectroscopy device. Anthropometric, laboratory, and other body composition parameters were recorded.

Results: The MIS was increased in patients with CKD. It was negatively correlated with body mass index (BMI), mid-arm muscle circumference (MAMC), handgrip strength, lean tissue index (LTI), fat tissue index (FTI), phase angle (PA), and hemoglobin and albumin concentrations, and it was positively correlated with sex, overhydration, urinary protein excretion and IL-6. A high MIS was significantly correlated with a low LTI ( $\mathrm{r}=-0.274 ; \mathrm{P}=0.001)$, low FTI ( $\mathrm{r}=-0.179 ; \mathrm{P}=0.032)$, overhydration $(\mathrm{r}=0.457 ; \mathrm{P}<0.001)$ and low $\mathrm{PA}$ $(\mathrm{r}=-0.475 ; \mathrm{P}<0.001)$. A rather strong correlation was observed between the PA and the MIS. In the multivariate regressions, after adjusting for age, sex, presence of diabetes, handgrip strength, BMI, overhydration, glomerular filtration rate, albumin and IL-6 concentrations, these relationships did not diminish.

Conclusions: The MIS was strongly linked with indicators of nutrition. As a simple and practical tool for assessing nutritional status, the MIS should be calculated in the early stages of CKD.

Keywords: Anthropometry; body composition; malnutrition-inflammation score (MIS); phase angle (PA); renal insufficiency; chronic

Submitted Mar 03, 2019. Accepted for publication Sep 24, 2019.

doi: 10.21037/apm.2019.10.12

View this article at: http://dx.doi.org/10.21037/apm.2019.10.12 


\section{Introduction}

Chronic kidney disease (CKD) is a global health problem with a prevalence of approximately $10 \%$ (1). Protein-energy wasting $(\mathrm{PEW})$ is a common complication of CKD and is thought to contribute to the high rates of morbidity and mortality observed in this population (2-4). It is characterized by inadequate nutrition and caloric intake, low body mass index (BMI), hypoalbuminemia, microinflammation status and progressive skeletal muscle loss (5). Although no single marker is ideal for assessing nutritional status in CKD patients, in whom various confounding factors such as fluid overload is common, the malnutrition-inflammation score (MIS), anthropometry, and body composition measurements (BCMs) are widely used methods for evaluating nutritional status (6-8). The MIS has been associated with poor outcomes in CKD patients undergoing hemodialysis, peritoneal dialysis, and kidney transplantation (9-13). In progressive CKD patients, the MIS has been validated for assessing nutritional status (14). However, CKD patients with malnutrition can hardly return to normal once malnutrition occurs. It is very important to detect and treat malnutrition in its early stages. To the best of our knowledge, to date, the utility of the MIS has not been assessed in the early stages of CKD. In this study, we evaluated whether the MIS could be used to assess nutritional status and whether it was associated with anthropometry and body composition in patients with CKD stages I-IV.

\section{Methods}

\section{Patients and study design}

We performed a cross-sectional study. The study was conducted in the Nephrology Department. All patients enrolled had a history of CKD of more than 3 months. A total of 177 patients were assessed for eligibility. A total of 33 patients were excluded because they either did not meet the eligibility criteria or refused to participate. Finally, a total of 144 patients with CKD were included in the study between May 2017 and December 2017 (Figure 1). CKD was diagnosed using the 2012 Kidney Disease: Improving Global Outcomes (KDIGO) criteria (15): glomerular filtration rate (GFR) less than $60 \mathrm{~mL} / \mathrm{min} / 1.73 \mathrm{~m}^{2}$ and/or kidney damage. The GFR was estimated with the CKD Epidemiology Collaboration (CKD-EPI) creatinine equation (16). We defined eGFR categories as follows: stage I, $\geq 90 \mathrm{~mL} / \mathrm{min} / 1.73 \mathrm{~m}^{2}$; stage II, 60-89 $\mathrm{mL} / \mathrm{min} / 1.73 \mathrm{~m}^{2}$; stage III, 30-59 mL/min/1.73 $\mathrm{m}^{2}$; stage IV, 15-29 $\mathrm{mL} / \mathrm{min} / 1.73 \mathrm{~m}^{2}$, respectively (15). The exclusion criteria were being less than 18 years of age, having end stage renal disease, having an acute kidney injury, having an acute infection during the month preceding inclusion in the study, having active cancer or liver disease at the time of the evaluation, and being unwilling to participate in the study or unable to give informed consent.

The underlying cause of CKD, the cardiovascular disease (CVD) history, and the presence of hypertension and diabetes mellitus were recorded in detail. The presence of a history of CVD was defined as myocardial infarction, angina pectoris, cerebrovascular accident, transient ischaemic attack, peripheral artery disease or revascularization diagnosed in the medical history (17). Hypertension was defined as a systolic blood pressure (SBP) $\geq 140 \mathrm{mmHg}$ or a diastolic blood pressure (DBP) $\geq 90 \mathrm{mmHg}$ on repeated measurements, or both, or by the use of antihypertensive drugs (18). Diabetes was defined as a fasting glucose level $\geq 7.0 \mathrm{mmol} / \mathrm{L}$, a glycated hemoglobin $\geq 6.5 \%$, or use of antidiabetic drugs (19). The study was approved by the Ethics Committee of Chinese PLA General Hospital (No. S2017-038-01), and all patients gave their written informed consent before their inclusion in the study.

\section{MIS}

The MIS is a scoring system for the assessment of malnutrition and inflammation. The MIS has 10 components derived from a patient's medical history, physical examination, BMI and laboratory parameters. Each component of the score is classified according to four levels of severity, ranging from 0 (normal) to 3 (severely abnormal). The sum of all 10 components of the MIS ranges from 0 (normal) to 30 (severe degree of malnutrition and inflammation). For the present analysis, given the nature of the included patients, we excluded dialysis vintage from the score. Thus, comorbidity was scored with a score of 0 if there were no other medical illnesses present; with a score of 1 for mild comorbidity, excluding such major comorbid conditions such as congestive heart failure class III or IV, severe coronary artery diseases, moderate-tosevere chronic obstructive pulmonary disease or major neurological sequels; with a score of 2 for moderate comorbidity (including one of the diseases listed under major comorbid conditions); and with a score of 3 for two or more major comorbid conditions. Furthermore, the serum total iron binding capacity was used instead of transferrin (9). 


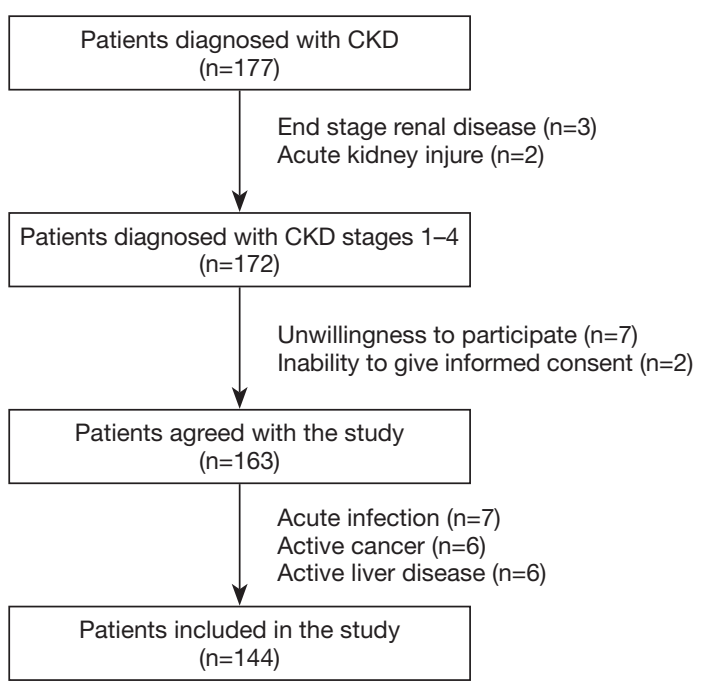

Figure 1 Patient flowchart.

All subjective MIS assessments were performed by the same physician.

\section{Anthropometric evaluation}

Body mass index (BMI), waist circumference, triceps skinfold thickness (TSF), mid-arm muscle circumference (MAMC) and handgrip strength were obtained within 1 week of the blood sample collection for the patients, and they were repeated three times. The average value was noted. The TSF was measured with a conventional skinfold caliper. The MAMC was derived from TSF and the middle arm circumference (MAC) as follows: MAMC $=$ MAC- $\pi$ *TSF $(\mathrm{cm})$. The MAC was measured on the dominant arm. Handgrip strength was measured in the dominant hand by using an electronic hand dynamometer (CAMRY, EH101).

\section{Body composition monitor (BCM) measurements}

Measurements of BCM were performed by a single welltrained staff using a portable whole-body bioimpedance spectroscopy device, BCM. The BCM measured the electrical responses at 50 different frequencies between 5 and $1,000 \mathrm{kHz}$. The input variables included the patient's height, weight, age, and sex. Electrodes were attached to the hand and foot on the nondominant side of the body after the patient had been in a recumbent position for at least $5 \mathrm{~min}$. The lean tissue index (LTI), fat tissue index (FTI), overhydration $(\mathrm{OH})$, total body water (TBW), extracellular water (ECW), intracellular water (ICW) and ECW/ICW were measured. The phase angle (PA) was calculated by the following equation: $\mathrm{PA}\left({ }^{\circ}\right)=($ Resistance/Reactance $)$ $\times(180 / \pi)$. Resistance and reactance were measured at $50 \mathrm{kHz}$ as in previous research reports (20). Only one $\mathrm{BCM}$ measurement was performed for each individual patient because the method had good interobserver and intraobserver reproducibility (21).

\section{Laboratory analysis}

Blood samples were collected in the morning after an overnight fast. Hemoglobin, C-reactive protein (CRP), IL-6, serum levels of albumin, prealbumin, transferrin, total cholesterol, triglycerides, parathyroid hormone $(\mathrm{PTH})$, and creatinine, and urinary protein excretion were measured by routine methods at the Department of Laboratory Medicine, PLA General Hospital. The GFR was estimated with the CKD Epidemiology Collaboration (CKD-EPI) creatinine equation.

\section{Statistical analyses}

The variables were expressed as the mean $\pm \mathrm{SD}$ or median (interquartile range, IQR) or as a percentage, as appropriate. Groups were compared by one-way ANOVA, the KruskalWallis test or $\chi^{2}$ analysis, as appropriate. As many values were not normally distributed, Spearman's rank correlation (Rho) was used to determine correlations. A determinant of the MIS was analyzed using linear multivariate regression analysis. Analyses were performed with IBM SPSS 23.0 software (SPSS Institute, IBM, USA). All P values were twosided. Statistical significance was set at the level of $\mathrm{P}<0.05$.

\section{Results}

\section{Baseline characteristics}

This study comprised 144 patients, median age 53 years (38-63 years of interquartile range). A total of 144 patients (94 men and 50 women) completed the measurements at baseline. The patients suffered from the following comorbidities: diabetes mellitus (33.3\%), hypertension (75.7\%) and CVDs (22.2\%). Patients were divided according to their CKD stages, and the demographic variables, anthropometric measurements, laboratory parameters, BCMs and the MISs of the study subjects are depicted in Table 1. 
Table 1 Demographic variables, anthropometric measurements, laboratory parameters, body composition and the MIS of study subjects stratified by CKD stages

\begin{tabular}{|c|c|c|c|c|c|c|}
\hline Characteristics (units) & $\begin{array}{l}\text { All patients } \\
\quad(n=144)\end{array}$ & $\begin{array}{l}\text { CKD stage I } \\
\qquad(n=30)\end{array}$ & $\begin{array}{l}\text { CKD stage II } \\
\qquad(n=36)\end{array}$ & $\begin{array}{l}\text { CKD stage III } \\
\qquad(n=57)\end{array}$ & $\begin{array}{l}\text { CKD stage IV } \\
\qquad(n=21)\end{array}$ & $\mathrm{P}^{\dagger}$ \\
\hline \multicolumn{7}{|l|}{ Demographic variables } \\
\hline Men (n, \%) & $94(65.3)$ & $20(66.7)$ & $22(61.1)$ & $37(64.9)$ & $15(71.4)$ & 0.884 \\
\hline $\begin{array}{l}\text { Cardiovascular } \\
\text { disease }(n, \%)\end{array}$ & $32(22.2)$ & $3(10.0)$ & $13(36.1)$ & $10(17.5)$ & $6(28.6)$ & 0.050 \\
\hline Hypertension (n, \%) & $109(75.7)$ & $15(50.0)$ & $27(75.0)$ & $48(84.2)$ & $19(90.5)$ & 0.001 \\
\hline \multicolumn{7}{|c|}{ Anthropometric measurements } \\
\hline $\mathrm{BMI}\left(\mathrm{kg} / \mathrm{m}^{2}\right)$ & $24.8(22.6-27.4)$ & 23.7 (21.2-27.0) & $24.9(23.3-27.6)$ & $26.1(23.2-27.7)$ & $24.4(22.8-27.1)$ & 0.278 \\
\hline $\begin{array}{l}\text { Waist circumference } \\
(\mathrm{cm})\end{array}$ & $91.3 \pm 11.7$ & $89.0 \pm 14.3$ & $90.6 \pm 12.1$ & $92.8 \pm 10.4$ & $91.3 \pm 10.5$ & 0.520 \\
\hline Handgrip strength (kg) & $28.8(21.7-38.0)$ & $28.8(21.4-38.7)$ & $28.0(20.8-36.3)$ & $29.6(22.4-41.0)$ & $26.1(22.1-35.5)$ & 0.888 \\
\hline \multicolumn{7}{|l|}{ Laboratory parameters } \\
\hline $\begin{array}{l}\text { eGFR } \\
\left(\mathrm{mL} / \mathrm{min} / 1.73 \mathrm{~m}^{2}\right)\end{array}$ & $57.5(37.5-86.7)$ & $107.7(100.6-122.4)$ & $72.7(66.5-85.1)$ & $41.4(37.3-52.0)$ & $21.3(18.8-26.1)$ & $<0.001$ \\
\hline $\begin{array}{l}\text { Urinary protein } \\
\text { excretion (g/24 hr) }\end{array}$ & $1.58(0.68-3.08)$ & $1.14(0.64-2.61)$ & $1.96(0.67-3.44)$ & $1.26(0.54-2.77)$ & $3.20(1.27-6.03)$ & 0.010 \\
\hline Hemoglobin (g/L) & $123.2 \pm 22.2$ & $136.2 \pm 18.7$ & $127.1 \pm 15.0$ & $119.6 \pm 23.8$ & $107.6 \pm 21.8$ & $<0.001$ \\
\hline Albumin (g/L) & $37.0(31.5-40.2)$ & $35.1(27.9-39.3)$ & $36.4(31.1-39.9)$ & $38.5(35.9-41.2)$ & $37.3(32.1-40.5)$ & 0.059 \\
\hline Prealbumin (g/L) & $30.1(24.4-35.2)$ & $26.7(21.9-36.8)$ & 30.1 (24.9-33.8) & $31.0(24.9-36.0)$ & $31.0(27.8-36.9)$ & 0.427 \\
\hline IL-6 (pg/mL) & $2.00(2.00-4.10)$ & $2.00(1.50-3.41)$ & $2.00(2.00-3.18)$ & $2.09(1.85-4.47)$ & $4.12(2.00-7.07)$ & 0.088 \\
\hline \multicolumn{7}{|l|}{ Body composition } \\
\hline $\mathrm{LTI}\left(\mathrm{kg} / \mathrm{m}^{2}\right)$ & $13.8 \pm 2.6$ & $13.6 \pm 2.9$ & $13.4 \pm 2.0$ & $13.8 \pm 2.6$ & $14.8 \pm 2.7$ & 0.235 \\
\hline $\mathrm{FTI}\left(\mathrm{kg} / \mathrm{m}^{2}\right)$ & $11.0(7.5-13.4)$ & $9.6(7.3-13.1)$ & $11.5(9.2-14.3)$ & $11.4(8.4-13.8)$ & $8.8(6.8-11.4)$ & 0.151 \\
\hline $\mathrm{PA}\left({ }^{\circ}\right)$ & $5.38 \pm 1.25$ & $5.64 \pm 1.07$ & $5.19 \pm 1.06$ & $5.50 \pm 1.34$ & $5.00 \pm 1.46$ & 0.207 \\
\hline $\mathrm{OH}(\mathrm{L})$ & $0.6(-0.3-1.9)$ & $0.1(-0.5-1.2)$ & $1.0(0.1-2.1)$ & $0.6(-0.4-2.1)$ & $1.5(0.2-5.5)$ & 0.028 \\
\hline TBW (L) & $35.5 \pm 6.5$ & $33.6 \pm 6.5$ & $35.2 \pm 5.8$ & $35.7 \pm 6.1$ & $37.9 \pm 7.9$ & 0.139 \\
\hline $\mathrm{ECW}(\mathrm{L})$ & $16.5(14.1-18.2)$ & $15.6(12.8-17.1)$ & $16.5(14.5-17.7)$ & $16.6(14.7-18.2)$ & $17.7(14.8-22.0)$ & 0.074 \\
\hline ICW (L) & $19.0 \pm 3.8$ & $18.4 \pm 4.0$ & $18.6 \pm 3.0$ & $19.2 \pm 4.0$ & $19.7 \pm 4.2$ & 0.585 \\
\hline ECW/ICW & $0.86(0.78-0.96)$ & $0.82(0.76-0.90)$ & $0.90(0.80-0.98)$ & $0.86(0.76-0.96)$ & $0.90(0.80-1.04)$ & 0.089 \\
\hline MIS & 3 [2-5] & $3[2-5]$ & $3[2-6]$ & $2[1-5]$ & $3[1-6]$ & 0.336 \\
\hline
\end{tabular}

${ }^{\dagger}, \mathrm{P}$ for trend from CKD stage 1 to 4 . BMI, body mass index; TSF, triceps skinfold thickness; MAMC, mid-arm muscle circumference; eGFR, estimated glomerular filtration rate; PTH, parathyroid hormone; CRP, C-reactive protein; LTI, lean tissue index; FTI, fat tissue index; $\mathrm{PA}$, phase angle; $\mathrm{OH}$, overhydration; TBW, total body water; ECW, extracellular water; ICW, intracellular water. 
Table 2 Univariate spearman rank correlation coefficients between the MIS and selected variables

\begin{tabular}{lrc}
\hline Variables & $r$ & $P$ \\
\hline Age (years) & 0.015 & 0.861 \\
Sex & 0.167 & 0.045 \\
Diabetes & 0.015 & 0.856 \\
BMI $\left(\mathrm{kg} / \mathrm{m}^{2}\right)$ & -0.262 & 0.002 \\
MAMC $(\mathrm{cm})$ & -0.317 & $<0.001$ \\
Handgrip strength $(\mathrm{kg})$ & -0.268 & 0.001 \\
LTI (kg/m $\left.{ }^{2}\right)$ & -0.274 & 0.001 \\
FTI (kg/m $\left.{ }^{2}\right)$ & -0.179 & 0.032 \\
PA ( $\left.{ }^{\circ}\right)$ & -0.475 & $<0.001$ \\
OH $(\mathrm{L})$ & 0.457 & $<0.001$ \\
eGFR $\left(\mathrm{mL} / \mathrm{min} / 1.73 \mathrm{~m}^{2}\right)$ & 0.112 & 0.181 \\
Urinary protein excretion $(\mathrm{g} / 24 \mathrm{hr})$ & 0.192 & 0.021 \\
Hemoglobin $(\mathrm{g} / \mathrm{L})$ & -0.330 & $<0.001$ \\
Albumin $(\mathrm{g} / \mathrm{L})$ & -0.583 & $<0.001$ \\
IL6 $(\mathrm{pg} / \mathrm{mL})$ & 0.189 & 0.023 \\
\hline
\end{tabular}

$\mathrm{BMI}$, body mass index; MAMC, mid-arm muscle circumference; $\mathrm{LTI}$, lean tissue index; FTI, fat tissue index; PA, phase angle; $\mathrm{OH}$, overhydration; eGFR, estimated glomerular filtration rate.

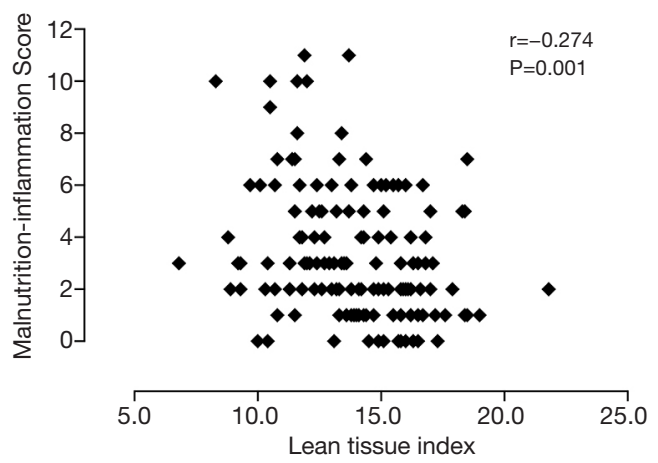

Figure 2 Spearman rank correlation between the malnutritioninflammation score and the lean tissue index in CKD patients. CKD, chronic kidney disease.

The patients suffering from diabetes mellitus and hypertension increased with the progression of CKD. The later CKD stages also had higher PTH and lower GFRs and hemoglobin concentrations than the earlier stages. $\mathrm{OH}$ was greater in patients with CKD stage IV than those with

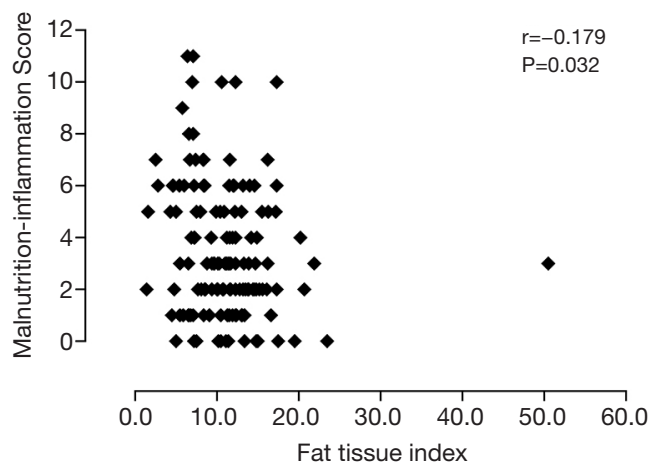

Figure 3 Spearman rank correlation between the malnutritioninflammation score and the fat tissue index in CKD patients. CKD, chronic kidney disease.

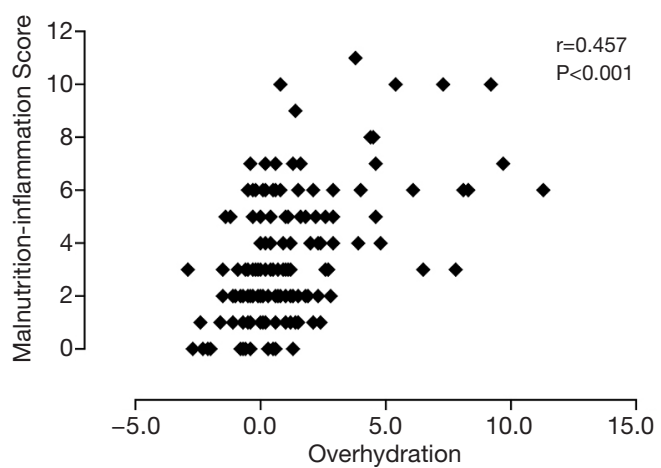

Figure 4 Spearman rank correlation between the malnutritioninflammation score and overhydration in CKD patients. CKD, chronic kidney disease.

other stages. Other body composition and anthropometric measurements and the MISs were not significantly different between the groups.

\section{Clinical associations of the MIS}

Table 2 shows univariate correlations among MISs and selected variables. MISs were negatively correlated with BMI, MAMC, handgrip strength, LTI, FTI, PA, and hemoglobin and albumin concentrations and positively correlated with sex, OH, urinary protein excretion and IL-6. A high MIS was significantly correlated with a low LTI $(\mathrm{r}=-0.274 ; \mathrm{P}=0.001)$ (Figure 2), low FTI $(\mathrm{r}=-0.179 ; \mathrm{P}=0.032)$ (Figure 3), high $\mathrm{OH}(\mathrm{r}=0.457 ; \mathrm{P}<0.001)$ (Figure 4) and small $\mathrm{PA}(\mathrm{r}=-0.475 ; \mathrm{P}<0.001)$ (Figure 5). A rather strong correlation was observed between the PA and the MIS. 


\section{Association between the MIS and the PA}

The significance of the association between the PA and MIS was explored through multiple linear regression analyses. The association remained statistically significant even after considering potential confounders such as age, sex, diabetes, HGS, BMI and OH, GFR, albumin concentration, and IL-6 (Table 3).

\section{Discussion}

Malnutrition was highly prevalent in patients with CKD and intimately linked with PEW. Our research evaluated the applicability of the MIS in patients with CKD stages I-IV. The use of the MIS had been previously validated in nondialysis CKD patients, and exclusion of dialysis vintage from the comorbidities section of the MIS did not impair the score's validity (14). Our research also excluded dialysis vintage from the score. We found that the MIS increased in the analyzed patients and shared strong links with objective indicators of body composition. The MIS could be a noninvasive and simple tool for testing nutritional status in

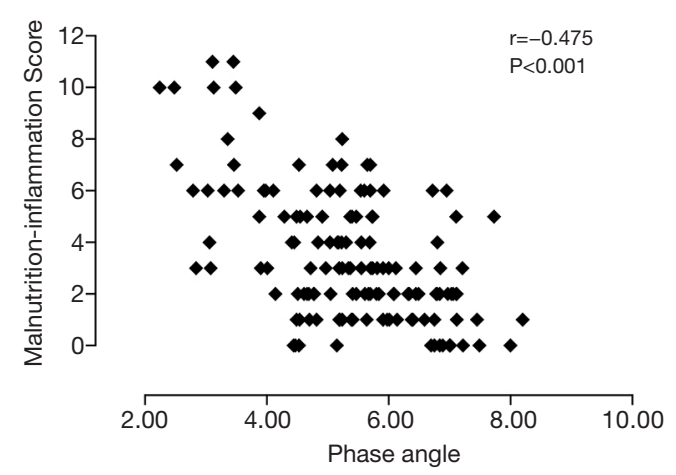

Figure 5 Spearman rank correlation between the malnutritioninflammation score and the phase angle in CKD patients. CKD, chronic kidney disease. the early stages of CKD. It was confirmed that higher MISs indicated a higher risk of poor clinical outcomes in CKD patients undergoing dialysis and kidney transplantation $(9,12,13)$. In the original MIS paper, increased scores were associated with poorer nutritional status and higher hospitalization and mortality rates (9). Thus, it was important to evaluate patients' nutritional status. We evaluated the applicability of the MIS in early-stage CKD patients with proteinuria but normal or mildly decreased GFRs. We also confirmed that the MIS increased in the early stages of CKD and that it was correlated with other nutritional status components. Whether higher MISs were related to malnutrition or mortality in these patients should be studied further.

The PA was another indicator used to assess nutritional status because it is related to cell size or the integrity of the cell membrane (22) and is less influenced by overhydration (23). Many studies emphasized the close association of nutritional status and the PA $(24,25)$. Oliveira et al. found that the PA was less influenced by changes in volume than other parameters and could be used for nutritional assessments in dialysis patients (25). In the maintenance hemodialysis population, the PA was a useful predictor for impaired muscle function and hospitalization and mortality rates (26). It was also useful to identify early and malnourished patients as a prognostic indicator in critically ill patients (27). The PA was independent of other measurements, such as weight and height and was calculated as the arctangent of the directly measured reactance-toresistance ratio (28). We demonstrated that the MIS was correlated with the PA, which was an objective indicator for assessing nutritional status even after considering potential confounders such as age, sex, presence of diabetes, handgrip strength, BMI, OH, GFR, albumin, and IL-6 in patients with CKD stages I-IV. Cohort research is needed to verify whether the MIS and the PA could be useful indicators of prognosis for these patients.

Table 3 Multiple linear regression analyses studying the association between the MIS and the PA in patients with CKD

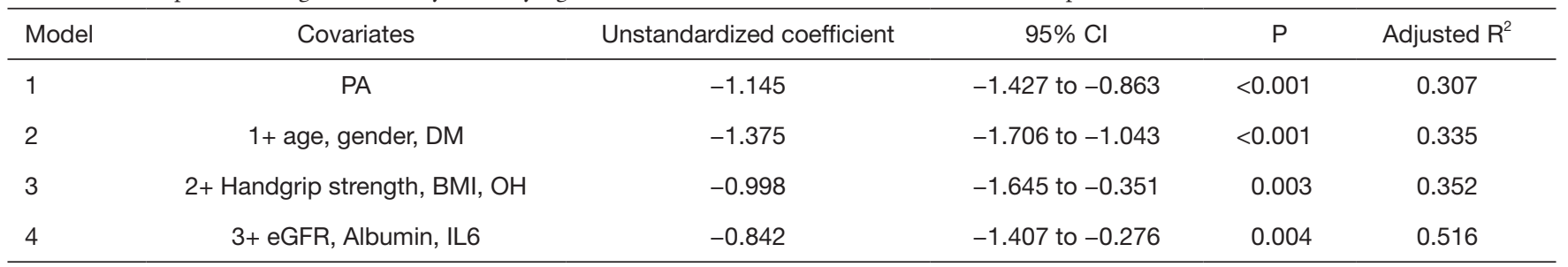

$\mathrm{Cl}$, confidence interval; PA, phase angle; DM, diabetes mellitus; BMI, body mass index; $\mathrm{OH}$, overhydration, eGFR, estimated glomerular filtration rate. 
Correlations between the MIS and BMI, MAMC, handgrip strength, LTI, FTI, OH were also found in the univariate analysis. Handgrip strength was a simple tool to assess muscle function, and it was confirmed as an effective method to assess nutritional status in patients with endstage renal disease (29). Reduced MAMC was a risk factor for mortality in incident hemodialysis patients (30). However, to better evaluate nutritional status, a combination of the MIS and other nutrition indicators need to be further studied.

Several limitations should be considered. First, the analysis used a cross-sectional design, and therefore, longitudinal relations between the studied factors and the MIS could not be established. Whether the MIS can influence clinical outcomes should be proven with a cohort study. Second, patients from a single center were enrolled, and a larger sample size is needed to confirm the conclusions from the study. However, we believe that it was unlikely that a larger sample size would have qualitatively changed our results.

In summary, the results of the current study suggest that the MIS is a simple and practical tool for assessing the nutritional status and implications thereof in CKD patients. The MIS and body composition should be evaluated in the early stages of CKD. Future studies testing the associations of MIS with clinical outcomes in this population are warranted.

\section{Acknowledgments}

The authors gratefully acknowledge the staff of the Department of Nephrology from Chinese PLA General Hospital for providing assistance to manage the patients.

Funding: This work was supported by the Science and Technology Project of Beijing (D181100000118004), the National Key Technology R\&D Program (2018YFA0108803), the National Key Technology R\&D Program (2015BAI12B06), the National Key Basic Research Program of China (973 Program) (2015CB553605).

\section{Footnote}

Conflicts of Interest: The authors have no conflicts of interest to declare.

Ethical Statement: The authors are accountable for all aspects of the work in ensuring that questions related to the accuracy or integrity of any part of the work are appropriately investigated and resolved. All procedures performed in this study involving human participants were in accordance with the ethical standards of the Ethics Committee of Chinese PLA General Hospital (No. S2017038-01) and with the 1964 Helsinki declaration and its later amendments or comparable ethical standards.

\section{References}

1. Jha V, Garcia-Garcia G, Iseki K, et al. Chronic kidney disease: global dimension and perspectives. Lancet 2013;382:260-72.

2. Fouque D, Kalantar-Zadeh K, Kopple J, et al. A proposed nomenclature and diagnostic criteria for protein-energy wasting in acute and chronic kidney disease. Kidney Int 2008;73:391-8.

3. Ikizler TA, Cano NJ, Franch H, et al. Prevention and treatment of protein energy wasting in chronic kidney disease patients: a consensus statement by the International Society of Renal Nutrition and Metabolism. Kidney Int 2013;84:1096-107.

4. Kovesdy CP, Kalantar-Zadeh K. Why is protein-energy wasting associated with mortality in chronic kidney disease? Semin Nephrol 2009;29:3-14.

5. Tennankore KK, Bargman JM. Nutrition and the kidney: recommendations for peritoneal dialysis. Adv Chronic Kidney Dis 2013;20:190-201.

6. Markaki A, Gkouskou K, Ganotakis E, et al. A longitudinal study of nutritional and inflammatory status in patients on dialysis. J Ren Care 2014;40:14-22.

7. Hou Y, Li X, Hong D, et al. Comparison of different assessments for evaluating malnutrition in Chinese patients with end-stage renal disease with maintenance hemodialysis. Nutr Res 2012;32:266-71.

8. Amparo FC, Cordeiro AC, Carrero JJ, et al. Malnutritioninflammation score is associated with handgrip strength in nondialysis-dependent chronic kidney disease patients. J Ren Nutr 2013;23:283-7.

9. Kalantar-Zadeh K, Kopple JD, Block G, et al. A malnutrition-inflammation score is correlated with morbidity and mortality in maintenance hemodialysis patients. Am J Kidney Dis 2001;38:1251-63.

10. Rambod M, Bross R, Zitterkoph J, et al. Association of Malnutrition-Inflammation Score with quality of life and mortality in hemodialysis patients: a 5 -year prospective cohort study. Am J Kidney Dis 2009;53:298-309.

11. Ho LC, Wang HH, Chiang CK, et al. Malnutritioninflammation score independently determined cardiovascular and infection risk in peritoneal dialysis 
patients. Blood Purif 2010;29:308-16.

12. He T, An X, Mao HP, et al. Malnutrition-inflammation score predicts long-term mortality in Chinese PD patients. Clin Nephrol 2013;79:477-83.

13. Molnar MZ, Czira ME, Rudas A, et al. Association of the malnutrition-inflammation score with clinical outcomes in kidney transplant recipients. Am J Kidney Dis 2011;58:101-8.

14. Amparo FC, Kamimura MA, Molnar MZ, et al. Diagnostic validation and prognostic significance of the MalnutritionInflammation Score in nondialyzed chronic kidney disease patients. Nephrol Dial Transplant 2015;30:821-8.

15. KDIGO. 2012 Clinical Practice Guideline for the Evaluation and Management of Chronic Kidney Disease. Kidney Int Suppl 2013;3:19-62.

16. Levey AS, Stevens LA, Schmid CH, et al. A new equation to estimate glomerular filtration rate. Ann Intern Med 2009;150:604-12.

17. Jie KE, Zaikova MA, Bergevoet MW, et al. Progenitor cells and vascular function are impaired in patients with chronic kidney disease. Nephrol Dial Transplant 2010;25:1875-82.

18. James PA, Oparil S, Carter BL, et al. 2014 evidence-based guideline for the management of high blood pressure in adults: report from the panel members appointed to the Eighth Joint National Committee (JNC 8). JAMA 2014;311:507-20.

19. Ene-Iordache B, Perico N, Bikbov B, et al. Chronic kidney disease and cardiovascular risk in six regions of the world (ISN-KDDC): a cross-sectional study. The Lancet Global Health 2016;4:e307-19.

20. Gupta D, Lammersfeld CA, Vashi PG, et al. Bioelectrical impedance phase angle as a prognostic indicator in breast cancer. BMC Cancer 2008;8:249.

21. Hung SC, Kuo KL, Peng CH, et al. Volume overload

Cite this article as: Wang WL, Liang S, Zhu FL, Liu JQ, Chen XM, Cai GY. Association of the malnutritioninflammation score with anthropometry and body composition measurements in patients with chronic kidney disease. Ann Palliat Med 2019;8(5):596-603. doi: 10.21037/apm.2019.10.12 correlates with cardiovascular risk factors in patients with chronic kidney disease. Kidney Int 2014;85:703-9.

22. Kyle UG, Genton L, Pichard C. Low phase angle determined by bioelectrical impedance analysis is associated with malnutrition and nutritional risk at hospital admission. Clin Nutr 2013;32:294-9.

23. Bosy-Westphal A, Danielzik S, Dorhofer RP, et al. Phase angle from bioelectrical impedance analysis: population reference values by age, sex, and body mass index. JPEN J Parenter Enteral Nutr 2006;30:309-16.

24. Maggiore Q, Nigrelli S, Ciccarelli C, et al. Nutritional and prognostic correlates of bioimpedance indexes in hemodialysis patients. Kidney Int 1996;50:2103-8.

25. Oliveira CM, Kubrusly M, Mota RS, et al. The phase angle and mass body cell as markers of nutritional status in hemodialysis patients. J Ren Nutr 2010;20:314-20.

26. Beberashvili I, Azar A, Sinuani I, et al. Bioimpedance phase angle predicts muscle function, quality of life and clinical outcome in maintenance hemodialysis patients. Eur J Clin Nutr 2014;68:683-9.

27. Reis de Lima e Silva R, Porto Sabino Pinho C, Galvao Rodrigues I, et al. Phase angle as an indicator of nutritional status and prognosis in critically ill patients. Nutr Hosp 2014;31:1278-85.

28. Kyle UG, Bosaeus I, De Lorenzo AD, et al. Bioelectrical impedance analysis-part II: utilization in clinical practice. Clin Nutr 2004;23:1430-53.

29. Chang YT, Wu HL, Guo HR, et al. Handgrip strength is an independent predictor of renal outcomes in patients with chronic kidney diseases. Nephrol Dial Transplant 2011;26:3588-95.

30. Araújo IC, Kamimura MA, Draibe SA, et al. Nutritional parameters and mortality in incident hemodialysis patients. J Ren Nutr 2006;16:27-35. 